\title{
Correction to: Improvement of Grey System Model using Particle Swarm Optimization
}

\author{
Elvis Twumasi ${ }^{1}$, Emmanuel Asuming Frimpong ${ }^{2^{*}} \mathbb{0}$, Daniel Kwegyir ${ }^{2^{*}}$ and Denis Folitse ${ }^{3}$
}

The original article can be found online at https://doi. org/10.1186/s43067-021-

00036-9.

${ }^{*}$ Correspondence:

eafrimpong.soe@knust.edu.gh

${ }^{2}$ Department of Electrical and Electronic Engineering, Kwame Nkrumah University of Science and Technology,

Kumasi, Ghana

Full list of author information is available at the end of the article

\section{Correction to: Journal of Electrical Systems and Inf Technol (2021) 8: 12 https://doi.org/10.1186/s43067-021-00036-9}

Following publication of the original article [1], the authors reported an error in the title and body text. The word "Grey" has been misspelt as "Gray".

The correct word "Grey" has been provided in this Correction.

The title name has revised to "Improvement of Grey System Model using Particle Swarm Optimization". The original article [1] has been updated.

\section{Author details}

${ }^{1}$ Department of Electrical and Electronic Engineering, University of Education, Winneba, Ghana. ${ }^{2}$ Department of Electrical and Electronic Engineering, Kwame Nkrumah University of Science and Technology, Kumasi, Ghana. ${ }^{3}$ Department of Statistics, Kwame Nkrumah University of Science and Technology, Kumasi, Ghana.

Published online: 15 June 2021

\section{Reference}

1. Twumasi E, Frimpong EA, Kwegyir D et al (2021) Improvement of gray system model using particle swarm optimization. J Electr Syst Inf Technol 8:12. https://doi.org/10.1186/s43067-021-00036-9

\section{Publisher's Note}

Springer Nature remains neutral with regard to jurisdictional claims in published maps and institutional affiliations. 